\title{
Research on the Construction of Practical Teaching System with Testing Features
}

\author{
Guiqin Xu \\ Department of Safety Engineering \\ China University of Labor Relations \\ Beijing, China
}

\begin{abstract}
In order to meet the social requirements of the practical ability of graduates, it is especially important for colleges and universities to establish a distinctive practice teaching system. This article analyzes the function of the practice teaching system and the common problems existing in practice teaching in colleges and universities at present. Combined with the characteristics of our school, a practical teaching system with the characteristics of a series of occupational hazard testing courses was built. The course of practical teaching featuring testing is improved from the aspects of teaching setup, teaching methods, training of teachers' practical abilities, and conditions for more students to participate in practical research projects. It has important application value in cultivating students' practice and innovation ability. As the only practical teaching system featuring with testing series of courses in our country, the construction of this system has an important reference value in the research of teaching reform.
\end{abstract}

Keywords - practice teaching system; occupational hazard testing; characteristics; occupational health

\section{The Role of Practical Teaching System AND the EXISTING PROBLEMS}

\section{A. The role of practice teaching}

Practice teaching refers to the practical activities that students begin to practice around the teaching goal. It covers experimental courses, professional training internships, curriculum design, graduation thesis (design) and various subject competitions. Practical teaching is one of the components of school teaching. It is an important teaching link in general undergraduate education. It is an important way for students to learn technical knowledge and cultivate practical ability ${ }^{[1]}$. The cultivation of innovative talents is not only an inevitable demand for the scientific development of colleges and universities and the growth of college students themselves, but also the urgent need of building an innovation-oriented country and the transformation of economic and social development. Practical teaching is an important teaching link in cultivating creative talents in colleges and universities. Promoting the reform and innovation of practical teaching and building a practical teaching system aiming at cultivating creative talents are of great significance to colleges and universities ${ }^{[2]}$.

China Institute of Industrial Relations Scientific research projects (17YY003)
With the deepening of "Teaching Quality and Teaching Reform Project in Colleges and Universities" in our country, practical education in colleges and universities has been greatly supported by government. A great deal of work have been done by all schools in the field of practice teaching, the number of practical teaching equipment and the allocation of practical teaching resources ${ }^{3]}$. However, the expansion of the mass scale often requires the protection of space, personnel and systems and does not directly bring about the maximum benefits. In order to give full play to the benefits of practical teaching resources, the internal soft power of colleges and universities, perfect the practical teaching management mode and operating mechanism should be improved, the innovation personnel training environment should be provided, an effective practice teaching system finally can be built.

\section{B. Existing problems in practical teaching}

All colleges and universities in the practice of teaching methods have many common problems as followed.

1) Practical teaching content need to be updated.

The existing practice content has been used for many years of training programs, which have stimulated students' strong interest and played a good training effect. However, with the development of society, if the elements of the times can't be infused into practical teaching, these relatively old trainings will be further away from reality, the enthusiasm of students will gradually decline, and the training effect will become worse and worse.

2) Practical teaching methods need to be reformed

Satirical education has always been our traditional idiom. This method can transmit the knowledge and experience of teachers to students as soon as possible, and can effectively prevent students from making detours and telling students the best path directly. This method requires a higher ability of teachers. For practical teaching teachers, it not only requires that teachers have a high level of knowledge, but also requires teachers to have rich practical experience. Even a good teacher can hardly cover the students' "passive" status. Student participation in the classroom is not high enthusiasm, playing mobile phones and even sleeping, truancy and other phenomena have occurred. 
3) Assessment of practical teaching needs to be improved

The existing practice teaching achievements include the composition of students' attendance, homework and examination, which are more objective, but the defects are also obvious ${ }^{[4]}$. The first is the emergence of attendance "alternative" or "to answer" phenomenon, attendance sometimes can't accurately reflect the reality of students. Followed by the phenomenon of job plagiarism serious, homework can no longer play the role of consolidation exercises. Finally, the examination questions to deal with, the original "relaxed" practice class has also become a "test-oriented" education model. The teachers who are not motivated do not pay attention to practical courses is another question.

Therefore, based on the actual social needs of higher engineering graduates, a practical teaching system is built which can meet the needs of national talents, students' employment and practical work. At the same time, the system of guarantee and supervision will be improved to meet the professional standards and objectives of practical ability.

\section{THE CONSTRUCTION OF PRACTICAL TEACHING SYSTEM}

The occupational health direction of safety engineering profession is by far the only one in the undergraduate security engineering profession in the country, so related to innovative personnel training mode, especially in practice teaching system, no other precedents of colleges and universities to follow. How to build a practical teaching system with practice ability as its core and how to raise the training quality of applied talents is a crucial issue. As an important part of undergraduate education, practical teaching is an important process of training students' experimental ability, practice and innovation, and also an important means of training high-level and innovative talents. The practical teaching level is also regarded as one of the important indicators for undergraduate teaching level evaluation in our country. Therefore, it is extremely important to establish the practical teaching system of safety engineering specialty occupational health in line with the requirements of innovative personnel training mode for theoretical research and practical application.

Therefore, according to the requirements of practice teaching in the curriculum of professional training program, the teaching program should be set up, the experiment center should be set up, the necessary practical teachers should be established, and the equipment needed to meet the practical needs should be provided. Work closely with the process of teaching, organize the implementation of practical teaching, to ensure teaching quality. Practical teaching system shown in Figure 1.

\section{The Characteristics OF THE Testing SERIES Courses OF PRACTICE TEACHING SYSTEM}

\section{A. Carrying out the practice of students' ability by occupational hazard testing series of practical courses}

Occupational Health Testing Courses is a core specialized course in the direction of occupational health in safety engineering which has outstanding practice and a wide range of application for students after graduation no matter study graduate students, engage in scientific research, or enter the enterprise, monitoring and testing agencies.

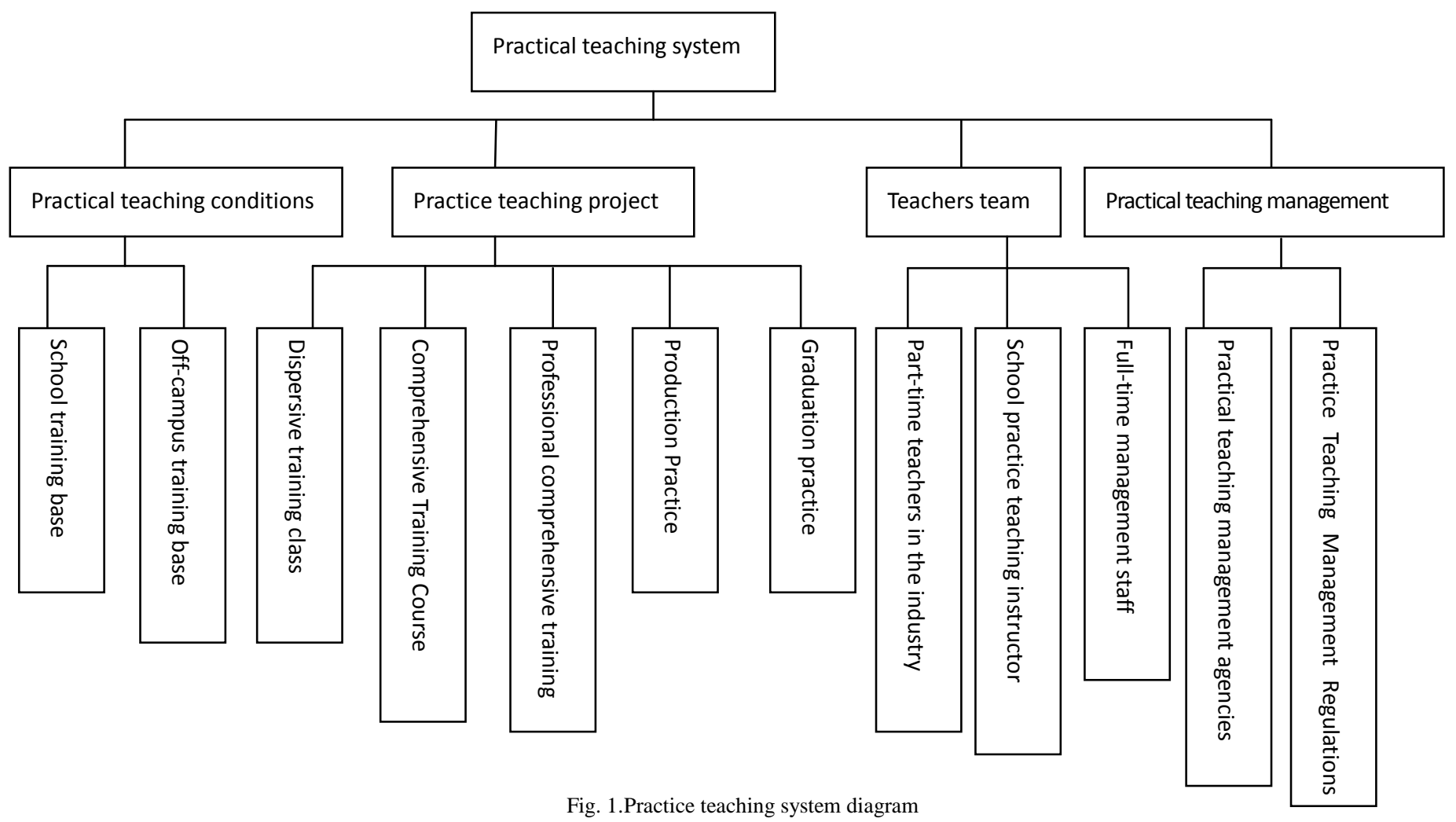


With the prominent problem of occupational health in our country, occupational health situation is becoming more and more serious. According to the Notice issued by the Central Government Office in October 2010, occupational health responsibilities is responsible by Safety Supervision Bureau. Since then, the State Administration of Work Safety has overall responsibility for the supervision and management of occupational health testing and evaluation. According to the Interim Provisions on Occupational Health Supervision at Workplaces promulgated by the State Administration of Work Safety, production and operation units that require occupational hazards shall be provided with special personnel to be responsible for routine monitoring of occupational hazards in the workplaces and to ensure that the monitoring system is in normal working condition. The production and business operation unit shall entrust an intermediary technical service agency with the corresponding qualification to carry out the testing of occupational hazards at least once every year and evaluate the status quo of occupational hazards at least once every three years. Therefore, the demand for technical services for occupational health is increasing. These conditions also determine the increase in demand for occupational health testing. According to the needs of the situation, combined with the status quo of my department, occupational health hazard testing series courses are suggested to be built as the characteristics the direction of occupational health. Testing laboratories have altogether be invested more than four hundred million Yuan of equipment, from the equipment point of view, to meet the occupational health test $\mathrm{B}$ laboratory qualification requirements. Courses in the testing direction include the course of occupational hazard detection techniques which is 32 hours, occupational hazard testing which is 32 hours and occupational hazard testing practice for one week.

Teaching mode is changed from theoretical-experimental mode to theory-comprehensive design research experiment-field practice. The first part, the theory of teaching links from teacher-based, into a guiding teaching. In the second part, the contents of the comprehensive experimental part of design are added, and the specifications need to be closely integrated with the requirements of practical work. The requirements of teachers for the experimental part are open, and only a few basic prerequisites must be met. For example, a complete sampling plan is required, and the experimental part of the design is required to meet the requirements of complete small scientific research projects such as experiment subjects, the choice of the sampling time, the determination of the influencing factors, the purpose of the experiment to be achieved, the problem to be explained through the design of a number of influencing factors, etc. The preparation of the experiment report focuses on the entire process of experimental design, experimental data processing and analysis, conclusion, suggestion. Through the design of the integrity of experiment, students not only understand the use of instruments, but also understand the solutions and methods of experimental research projects. In the meantime, students are required to familiarize themselves with the relevant standards. The third part is to practice outside the school for on-site internships. Students need to complete the entire testing procedure from on-site investigation, program formulation, pre-test preparation, on-site sampling on-site testing, laboratory testing, and data processing to testing reports. On the basis of the theoretical courses and experimental courses, further on-site practice is the necessary supplement to increase the ability to link theory with practice and solve practical problems.

The reform evaluation method is changed too. The assessment principle of practice course is to encourage students to think and practice more, to avoid mechanically, stereotyped experimental report. Since the requirements of the experimental program are comprehensively designed and experimentally-based, the experiment report submitted by each person must be unique and the experiment allows mistakes or even errors. However, students are required to be able to judge whether the experimental data are reasonable or not, analyze the data, analyze the cause of the error, and the deficiencies of the experimental reports. As long as the problem can be found, The students who can analyze the problem, have the ability to solve the problem will be scored an excellent experiment report.

\section{B. Enhance teachers' ability to practice testing}

In the practice teaching faculty, the relevant aspects of construction are improved gradually. First of all, increase the training of full-time teachers, encourage teachers to strengthen their practical contacts with enterprises and encourage teachers to attend training. At present, teachers related to the occupational health research direction are all or part of them obtained the qualification of registered safety engineers, occupational health testing and evaluation of qualifications, registered occupational hygienist. Second, employ front-line staff to do part-time teachers. Thirdly, in some practice internship, enterprises technicians are hired as part-time instructors to assist students in internship so that students' internship can be more fit the actual situation and further improve the internship effect.

\section{C. students in-depth and active participation in teacher research projects, improve the ability of scientific research and practice}

Nearly $30 \%$ of undergraduate students enter the laboratory to participate in the teacher's research project related to testing. This greatly enhances the students' scientific research vision and experimental ability, which provides great help to students after they graduate and take up their jobs.

\section{CONCLUSION}

A practical teaching system of occupational health direction of safety engineering specialty is constructed. The teaching system features which is a series of occupational hazard testing courses to enhance students practice and quality of innovation and training of teachers' practical ability. At the same time, it increases the participation of students in the scientific research of teachers and enhances the practical ability, scientific research ability and hands-on opportunities of students in occupational health. 


\section{REFERENCES}

[1] Niu Qingwei, Wei Hu, Liu Zhen. Research and Practice of Practical Teaching System for Cultivating Students' Creative Ability. Chinese University Teaching. pp.70-73, October 2011.(In Chinese)

[2] Yuan Yinan, Xu Zhenying, Liu Huixia, et al. Perfecting practice teaching system and strengthening innovation ability training. Laboratory Research and Exploration, pp 93-98, April 2010. (In Chinese)
[3] Li Hongyang, Wang Lifeng. Construction of Experimental Teaching Demonstration Center in Colleges and Universities and Cultivation of Innovative Talents. Experimental Technology and Management, pp 111-114, September 2010. (In Chinese)

[4] Zhou Xu Zhang, Wang Caisheng, Cai Yan, and so on. Construction of training high-quality engineering practical talents practical teaching system Laboratory Research and Exploration, pp125-127, December 2010. (In Chinese) 